\title{
Crystal Wall Gazing (or: No Vacancy)
}

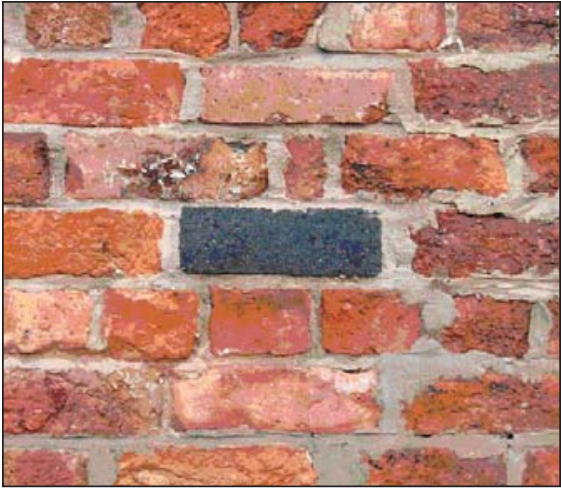

Figure 1. A substitutional atom.

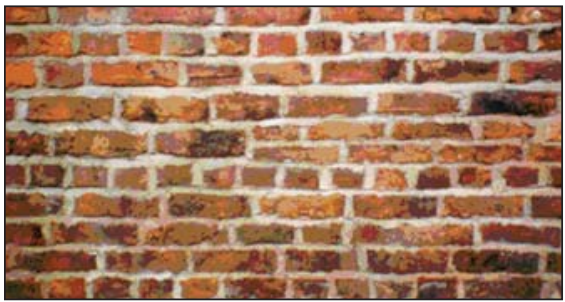

Figure 2. An edge dislocation.

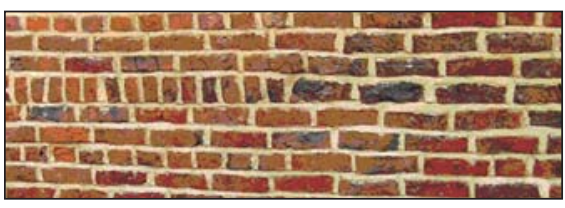

Figure 3. An edge dislocation with segregated large atoms.

I recently read Bleak House for the first time, my early exposure to Dickens having been limited to Oliver Twist, A Christmas Carol, and Great Expectations. It becomes immediately apparent, reading as an adult, that Dickens was a master of metaphor and simile. Not a page goes by without the coinage of a startlingly apposite comparison of some aspect of human behavior with some other familiar feature of 19th century life. The 21st-century scientist's equivalent tools tend to be analogies and models, but their purpose is the same-to make the topic clear and memorable.

Bleak House, in common with most houses in the United Kingdom, is built of brick and stone. In my professional educator's constant quest for models to help explain and enliven my subject matter, I have been gazing intently at walls. At first glance, a wall displays the character-
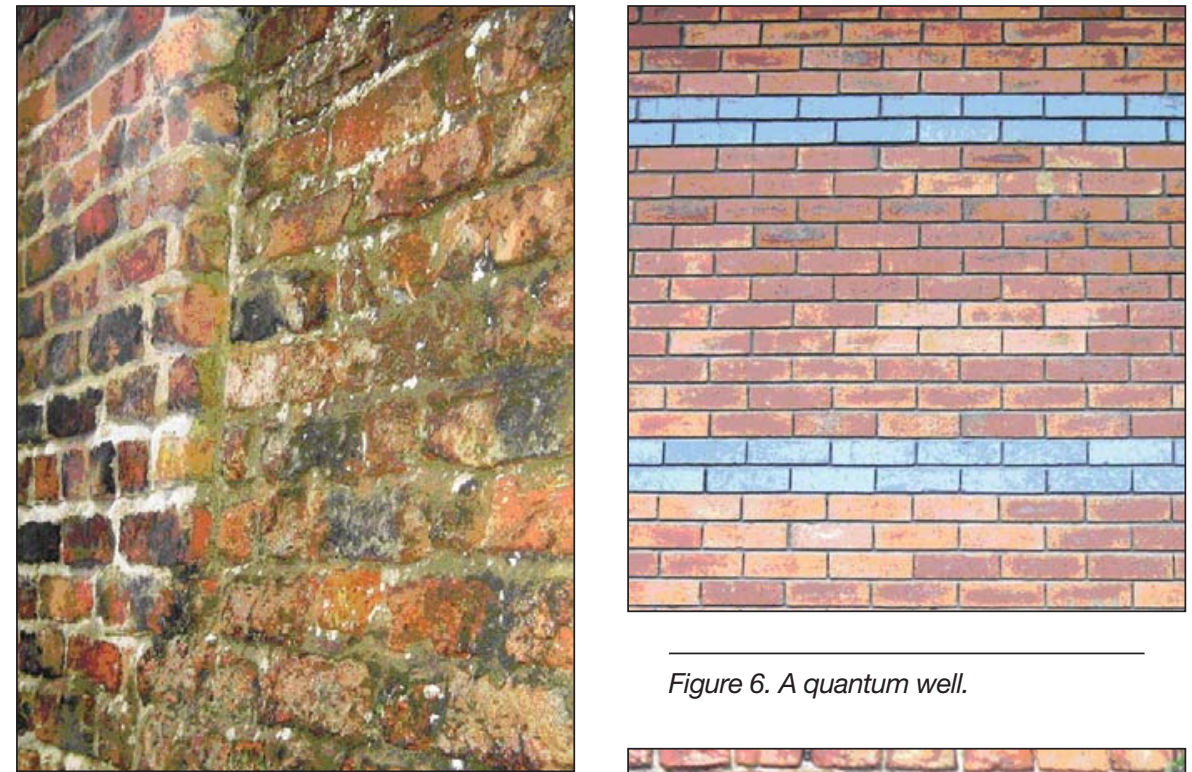

Figure 6. A quantum well.

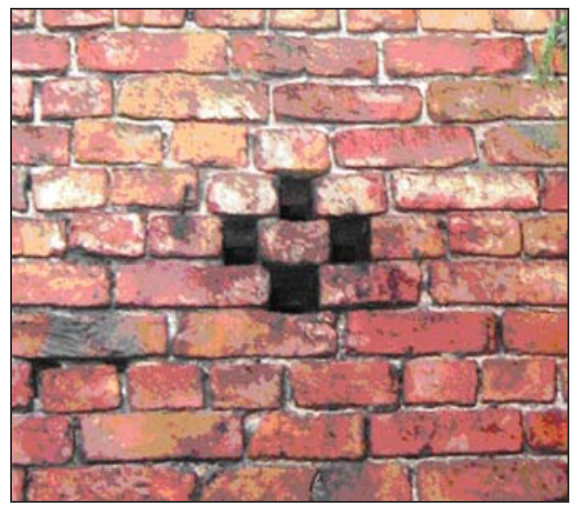

Figure 5. A delta-doped region.

istics of a two-dimensional crystal-it has a lattice upon which is repeated a motif (usually no more than one or two bricks). So far, so boring. However, to my initial surprise but lasting delight, older walls frequently display evidence for all manner of crystal defects.

Substitutional atoms are easily found (Figure 1), but the first line defect I spotted was an edge dislocation (Figure 2), then another, with a plane of larger atoms (Figure 3). More surprising was the emerging surface step revealing the presence of a screw dislocation (Figure 4). Now I was really tuned in, so deltadoping layers (Figure 5) and quantum wells (Figure 6) leaped to my attention. My latest discovery is a tetravacancy (Figure 7) which at a far-distant point of my early career I might have accused of being the nucleus for a stacking fault tetrahedron. I have also spotted, but have no space to show, ordered crystals, nonclose-packed structures, and inter-phase boundaries galore. The most difficult defect to spot has been the vacancy-I have a couple of rather poor examples, but no crisp single vacant site- obviously the formation energy is far too high.

All the walls I have used in this article lie on the routes I take in my daily lifethey are in my home village, my local city (Chester), and on my walking route from Lime Street Station to the University of Liverpool. If any reader spots other would send me an image-who knows, there might be a coffee-table book here (or should it be, nowadays, a coffee-break Web site?)!

PETER GOODHEW Goodhew@liv.ac.uk pcwww.liv.ac.uk/ goodhew examples, I would be grateful if you 